\title{
The European Society of Peadiatric Radiology
}

\author{
Search for a new European Managing Editor
}

Published online: 10 July 2015

(C) Springer-Verlag Berlin Heidelberg 2015

The European Society of Paediatric Radiology is seeking applications and nominations for the position of the European Managing Editor for the journal Pediatric Radiology.

Pediatric Radiology is the official journal of the European Society of Paediatric Radiology (ESPR), the Society for Pediatric Radiology (SPR), the Asian and Oceanic Society for Pediatric Radiology (AOSPR) and the Latin American Society of Pediatric Radiology (SLARP). The journal is the only journal dedicated exclusively to the subspecialty of pediatric radiology and a primary source of information to the international community of pediatric radiologists.

The journal receives submissions on all aspects of pediatric radiology from all over the world and publishes scientific articles and review articles on timely topics. The journal is under the leadership of two Managing Editors, one from Europe affiliated with the ESPR and one from America affiliated with the SPR, and a close working relationship between the two Managing Editors is indispensable for the consistency of the journal. The European Managing Editor is responsible for manuscripts submitted from Europe and all other countries with the exception of manuscripts originating from the Americas. The two Managing Editors account for the content of the journal. This includes acquiring, reviewing and collating manuscripts for publication in a timely manner as well as corresponding with the Editorial Board, reviewers and authors. In addition, the Managing Editors arrange supplements on topics of interest to the international community of pediatric radiologists. Furthermore, the Managing Editors appoint the Editorial Board.

The ideal candidate should have a vision of how to lead the journal and increase its impact in the international community, as well as the desire to continue a close working relationship with his/her American colleagues. The candidate should have a broad interest and experience in pediatric radiology and research, a commitment to leading this journal to a preeminent position in the specialty, and a clear idea of the pragmatic issues involved in accomplishing this mission. Successful applicants will have previous experience as journal editor of a peer-reviewed journal.

The new European Managing Editor will be appointed by the publisher in consultation and agreement with the European Society of Paediatric Radiology (ESPR). The European Managing Editor is expected to work closely with the publisher on all aspects of publishing, to be an active member of the ESPR and to liaise with the ESPR leadership and the membership-atlarge.

Each interested individual is invited to forward his or her name, a succinct letter of interest and qualifications, a 2-page vision statement and curriculum vitae to the chairman of the ESPR Publications Committee:

\section{Dr. Veronica Donoghue}

c/o ESPR - European Society of Paediatric Radiology

Neutorgasse 9/2 I 1010 Vienna I Austria

office@espr.org

Submissions should be received by $\mathbf{2 4 / 0 8 / 2 0 1 5}$. 